\title{
PROSTATO-CYSTOPEXY FOR A PARAPLEGIC CASE WITH AN INACTIVE BLADDER AND PERINEUM
}

\author{
By P. Dollfus, F. Jurascheck, D. Jacob-Chia and R. Peter \\ Centre de Readaption, Mulhouse, France
}

THE combination of an easily distending lower motor neuron bladder and an atonic pelvic floor can result in a total impossibility, in certain cases, of voiding without surgical interference. In most cases, a single, or repeated T.U.R., of the bladder neck, is sufficient. However, if this, or these, should fail, the cause of retention must be found out, and in some cases, such procedures as an Y-V prostato-urethroplasty, or even electrostimulation, have been advocated to avoid a permanent indwelling catheter. In true L.M.N. lesions the missing contraction of the detrusor is replaced by abdominal strain, associated, or not, by 'Credé pressure'. This is sufficient as long as the internal sphincter is permeable. When this is not, the combination of back- and down-tilting of the bladder base, and

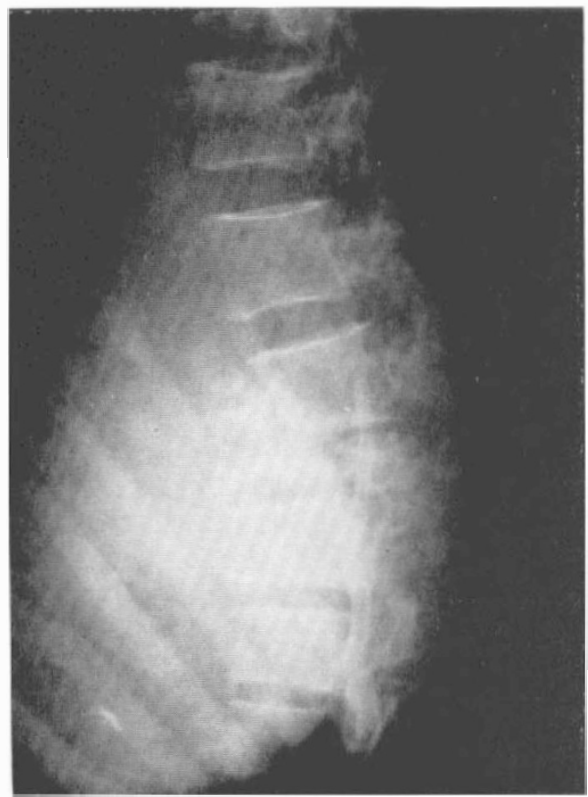

FIG. I

Case report, Male, aged 45. Complete permanent flaccid paraplegia, below TI I on the right, LI on the left, due to communitive fracture of $\mathrm{LI}$. posterior wall, pressing on the atonic pelvic floor will displace backwards the resultant of the intravesical forces exerted by the abdominal strain, literally missing the internal sphincter, furthermore the stretching of the pubo-vesical ligaments will enhance this phenomenon even more.

\section{CASE REPORT}

Our patient, a gentleman aged 45 , on whom we are giving this preliminary report, sustained in April 1970 a severe accident resulting in multiple injuries with a complete permanent flaccid paraplegia, below Ti I on the right, $L_{I}$ on the left, due to a comminutive fracture of $\mathrm{LI}_{\mathrm{I}}$ (fig. I). $\mathrm{He}$ was transferred the same day to the accident unit of Colmar, where his bladder paralysis was treated by intermittent catheterisation for four months without a single episode of infection. After, he was transferred to the rehabilitation centre of Mulhouse where the same treatment was carried out. One month later, having not passed urine, a T.U.R. of the bladder neck was performed, without result, the urine having become infected. One month later, another T.U.R. of the bladder neck was performed with a fairly good, but not lasting result, as two months later the residual urine had risen to half of the bladder capacity. On examination by image intensifier and cineradiography, in oblique position, it was noticed that the bladder was 
literally sinking backwards into the pelvis (figs. 2 and 3) resulting, on straining, in a kink between the prostatic and membranous perineal urethra. A third endoscopic examination was performed and a plicated mucous valve removed between 7 and ro o'clock below the veru montanum, although this valve was only seen on slow withdrawal of the cystoscope. (This might have been a primary, or secondary cause, as an obstacle to the urine flow, as no stricture could be found.) Again a fairly good result was obtained but only temporarily until April this year. It was then decided to perform a prostatocystopexy after hearing of the good result of a cervico-cystopexy performed by our friend, J. P. Archimbaud of Lyon, in a complete, very low cauda equina lesion case with additional anterior fixation of the sigmoid colon to the abdominal wall, curing a rectal prolapse.

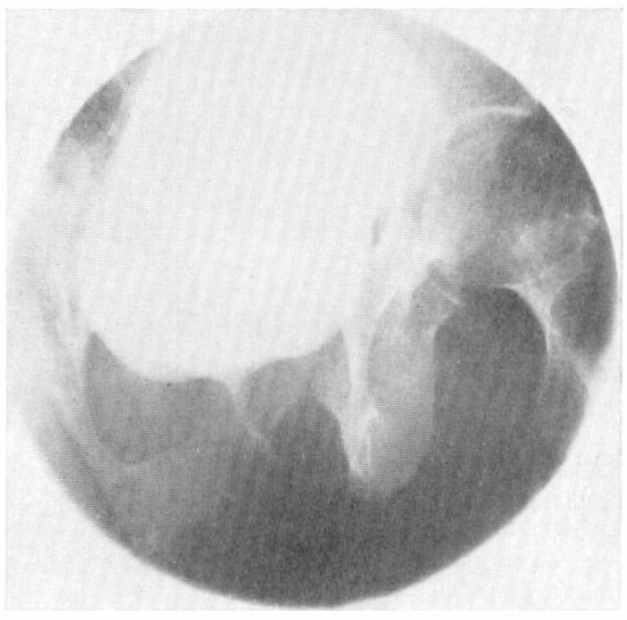

FIG. 2

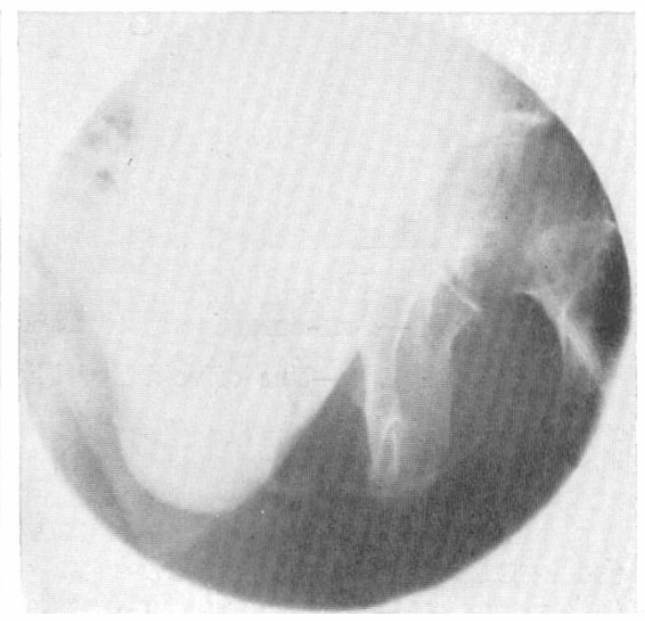

FIG. 3

Fig. 2.-Pre-operative bladder-filled cystogram (resting position).

Fig. 3.-Attempt to void (abdominal strain). Note urethral kink.

In our patient, the anterior part of the prostate was fixed on the pubis and to the retropubic ligaments according to a technique similar to that of Perrin (1944), in women with stress incontinence, and the anterior part of the bladder anchored to the rectus fascia on both sides. The prevesical cul-de-sac having been reclined upwards, a fairly correct angle between the bladder and internal sphincter was achieved, as, at the same time, the urethral kinking, during abdominal strain, disappeared.

\section{RESULT}

The clinical picture improved dramatically, the residual falling to a very low figure of $10-20 \mathrm{ml}$. for a capacity of $450-500 \mathrm{ml}$. (figs. 4 and 5) with an average urine flow rate of 7-8 ml./second. At times, however, it has become necessary for our patient to press his perineum upwards with his fingers, to give an additional support to the posterior bladder wall (film). The urine is now sterile. At no time was reflux detected and the latest I.V.P., in May this year, was normal. 


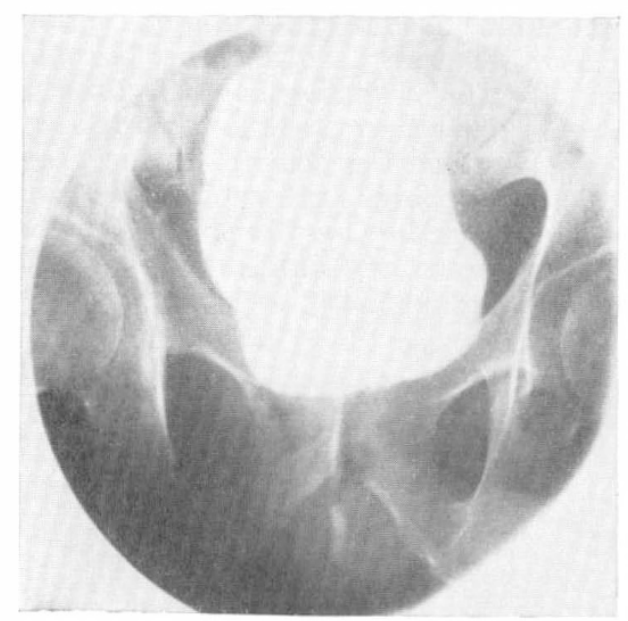

FIG. 4

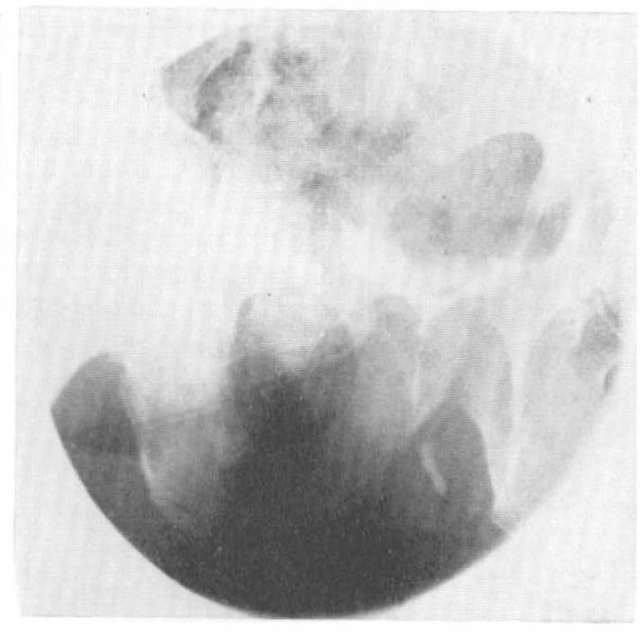

FIG. 5

Fig. 4.-Post-operative cystogram. Patient voiding by abdominal strain.

Fig. 5.-End of voiding (oblique view). Residual urine $20 \mathrm{ml}$.

\section{DISCUSSION}

Different techniques to increase voiding pressure have been described since the attempt of Rochet of Lyon, as early as I9II, to reneurotise the bladder (Thevenot, I9I3). Other techniques applying, directly, or indirectly, the muscle strength of the recti to the bladder have been reviewed, as paraplegics are concerned, by Heusser and Rutishauser (1960) and by Bors and Comarr (1971). Cervico-cystopexy for women with stress incontinence has been described by Perrin of Lyon in 1946 and a very wide number of similar operations in the medical literature have been used in non-paraplegic patients with stress incontinence. Our goal was to achieve, on the contrary, a fair degree of incontinence!

J. P. Archimbaud, in his case, wanted by cervico-cystopexy, to achieve voiding in an erect position for his patient who could only micturate in the position of the Mohammedan Prayer, thus tilting his denervated bladder forward and at the same time giving a back support to the posterior wall of the bladder by lifting and fixing forward the sigmoid colon to the abdominal wall according to the technique of Lahaut (1956), thus preventing the occurrence of a rectal prolapse. The association of both procedures would be, according to him, the best, as this type of bladder will always have a tendency to unfold backwards and downwards.

\section{CONCLUSION}

The evolution of this type of denervated bladder and perineum will be a problem in the future of such patients, and only preliminary reports can be given. Such an operation should be performed only in very selected cases, and after a careful and repeated dynamic examination in lateral position, overstretching of the pubo-vesical and prostatic ligaments must be watched for. 


\section{SUMMARY}

A prostato-cystopexy was performed in a case of paraplegia with a complete flaccid lesion with an inactive bladder and perineum, due to the back-tilting of the bladder and overstretching of the pubis-vesical ligaments. A good result was achieved with a low residual but a diminished urine outflow.

\section{Resumé}

Une prostato-cystopexie a été effectuée dans une paraplégie flasque et complète chez qui la vessie basculait en arriére avec une distention des ligaments pubo-vésicaux. Un bon résultat a été obtenu avec un résidu bas mais un débit mictionnel diminué par rapport à la normale.

\section{ZUSAMMENFASSUNG}

Eine Prostato-Cystopexie wurde bei einer komplette schlaffe Paraplegie durchgeführt in welcher die Blase nach hinten schwenkte mit einer Ausdehnung der Ligamente pubovesicalia. Mann ereichte ein guter Erfolg mit einem geringen Restharn und mit vermindertem Urinminutvolum.

\section{REFERENCES}

Archimbaud, J. P. (I97I). Personal communication.

Bors, E. \& Comarr, A. E. (I97I). Neurological Urology, 239-240. Karger, Basle.

Goetzen, F. J. and Boeminghaus, H. (1954). Z.Urol. 47, I37-I60.

Heusser, H. \& Rutishauser, G. (1960). Helv. Chir. Acta, 27, 292-298.

LAHAUT, M. (1956). Fournal de Chirurgie, 72, 565-569.

Perrin, E. (I946). Lyon Chir. 4I, 270-278.

Thevenot, L. (1913). Progr. méd. 4I, 65I-652. 